\title{
Atuação do psicólogo em saúde do trabalhador na perspectiva psicossociológica
}

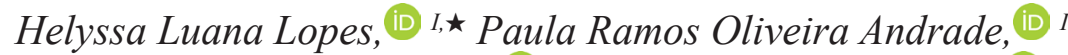 \\ Valéria Morais da Silveira Sousa, (DD) I Maria Teresa Pires Costa, (D) II \\ ${ }^{I}$ Universidade Estadual da Paraíba, Campina Grande, PB, Brasil \\ ${ }^{\text {II }}$ Universidade Federal do Rio Grande do Norte, Natal, RN, Brasil
}

Resumo

O campo da Saúde do Trabalhador, disposto a estudar e a intervir nos processos de saúde e doença, tem dialogado com diferentes áreas do conhecimento no intuito de melhor compreender a complexidade presente nesta interação, considerando a diversidade de fatores que podem interferir nos níveis de saúde experimentados pelas pessoas. Em meio ao crescente interesse pelo campo, se faz pertinente questionar como a ciência psicológica tem se posicionado a respeito das repercussões do trabalho sobre a mente humana. Para tanto, o presente estudo propõe identificar em que medida a atuação do psicólogo em saúde do trabalhador tem contemplado os pressupostos da abordagem psicossociológica. Através das bases de dados SciELO (Scientific Eletronic Library Online) e LILACS (Literatura Latino Americana e do Caribe de Informação em Ciências da Saúde) realizou-se uma revisão integrativa da literatura, a fim de compilar informações que viabilizassem a síntese do estado do conhecimento da temática em questão. Foi possível identificar a necessidade de um maior investimento em termos de pesquisa e de intervenção no campo saúde do trabalhador fundamentados nos pressupostos psicossociológicos.

Palavras-chave: saúde; trabalho; abordagem psicossocial; atuação do psicólogo.

\section{Psychologist acting on worker health in psychosociology perspective}

\begin{abstract}
The field of Worker Healt, willing to study and intervene in health and disease processes, has dialogued with different areas of knowledge in order to better understand the complexity present in this interaction, considering the diversity factors that can interfere in the health levels experienced by people. Amid the growing interest in the field, it is pertinent to question how psychological science has positioned about the repercussions of work on the human mind. Therefore, this study intends to identify to what extent the psychologist in worker health has contemplated the assumptions of psychosociology approach. Through SciELO (Scientific Eletronic Library Online) and LILACS (Latino Literature American and Caribbean Center on Health Sciences) databases we used an integrative literature review, in order to compile information that would enable the synthesis of the state of knowledge of the subject in question. It was possible to identify the need for greater investment in research and reasoned intervention in psychosociology assumptions of the universe of the health workers.
\end{abstract}

Keywords: health; work; psychosociology approach; psychologist's performance.

\section{Introdução}

Certamente, quando o indivíduo se vincula a qualquer situação de trabalho, seja ela formal, informal, autônoma ou temporária, diversas variáveis atuam sobre ele e passam a interferir no seu estado pessoal, na saúde, nas relações sociais e no próprio trabalho. De fato, a literatura tem apontado que as transformações na organização, nos processos e nas relações de trabalho se intensificaram desde o final do século XX em face do processo de reestruturação produtiva, resultando num quadro de agravamento e precarização das condições de trabalho que interfere direta e variadamente nas vivências de saúde dos trabalhadores (ALVES; VIZZACCARO-AMARAL; MOTA, 2011; SELIGMANN-SILVA, 2011; NELI, 2006; ANTUNES; ALVES, 2004).

Nesse sentido, as relações entre saúde-doença e trabalho vêm sendo cada vez mais evidenciadas nos contextos laborais e acadêmicos, sendo um dos eixos centrais na análise dos fenômenos inerentes ao ato de trabalhar e das transformações sociais produtivas. Congregando saberes e práticas de diferentes disciplinas, o campo da

\footnotetext{
^Endereço para correspondência: Universidade Estadual da Paraíba. Rua Baraúnas, 351 - Bairro Universitário - Campina Grande, PB - Brasil. CEP 58429-500. E-mails: helyssa.luana@hotmail.com,proandrade@yahoo.com.br,proandrade@ yahoo.com.br, valeriamorais1803@hotmail.com, teresapires.psi@gmail.com Os dados completos das autoras encontram-se ao final do artigo.
}

Saúde do Trabalhador constitui importantes aportes teórico-metodológicos, disposto a estudar e intervir nos processos de saúde e doença em sua interação com o trabalho. Conforme Gomez (2011), tal campo surge tendo por referência fundamentos da Saúde Ocupacional e da Medicina Preventiva cujas medidas asseguram parcialmente a saúde do trabalhador, uma vez que valorizam os riscos mais evidentes e de cunho individual. Logo, a ênfase recai no uso de equipamentos de proteção e na elaboração 'artificial' de normas e procedimentos para segurança no trabalho, culminando num quadro de prevenção visivelmente simbólico, que pouco se debruça sobre as reais demandas dos trabalhadores.

A partir da década 1980, o campo passa a sofrer fortes influências da Reforma Sanitária e da Medicina Social Latino-Americana; amplia sua proposta e finalmente passa a ter políticas contempladas no sistema público de saúde (LACAZ, 2007; GOMEZ, 2011). Busca-se então ir além dos métodos de prevenção de riscos e acidentes, priorizando a participação do trabalhador, ao resgatar o sentido positivo do trabalho e sua capacidade protetora de agravos à saúde até então pouco evidenciada. Enquanto campo de saber próprio da Saúde Coletiva, deve primar pela interdisciplinaridade e dialogar com variadas disciplinas, como Sociologia, Psicologia, Engenharia, Epidemiologia, dentre outras, a fim de analisar e intervir profundamente

Recebido em: 17 de agosto de 2016

$1^{\text {a }}$ avaliação: 25 de outubro de 2019 $2^{\mathrm{a}}$ avaliação: 26 de outubro de 2019 Aceito em: 8 de janeiro de 2020 
nos processos de trabalho, visando, sobretudo, "identificar as transformações necessárias a serem introduzidas nos locais e ambientes para a melhoria das condições de trabalho e saúde" (GOMEZ; LACAZ, 2005, p. 799).

Ao refletir sobre a configuração do campo Saúde do Trabalhador, Lacaz (2007) problematiza avanços e retrocessos de suas bases constitutivas: a produção acadêmica, a programação em saúde na rede pública e o movimento dos trabalhadores a partir dos anos de 1980. Logicamente esses são pilares inacabados que demandam árduo investimento e aperfeiçoamento contínuo, a fim de fortalecer e impulsionar o desenvolvimento do campo por meio de ações mais condizentes com as necessidades e demandas dos trabalhadores, conforme assinalado por Gomez (2011), quando afirma que a produção dos saberes e as práticas em Saúde do Trabalhador ainda se encontram fragmentadas e carecem de embasamentos prioritariamente articulados com a realidade operária e a participação ativa do trabalhador e de seus sindicatos.

Sobretudo, Lacaz (2007) considera que, se nos anos de 1980 o protagonismo dos trabalhadores se caracterizou pela participação e controle social, atualmente o que se observa é a fragilidade dos sindicatos. Para o autor, a produção acadêmico-científica pautada na perspectiva multi/interdisciplinar e nos pressupostos do campo da Saúde do Trabalhador tem se mostrado com diferentes configurações, inclusive com tendência tecnicista. Ao mesmo tempo, o que hoje se vê no que diz respeito à programação em saúde na rede pública é uma reaproximação com as bases da Saúde Ocupacional e o resgate de suas formulações. Esta breve análise aponta para indicativos não somente de entraves ao avanço do campo, mas de um expressivo retrocesso.

No que se refere às políticas públicas e aos aspectos legais que amparam as ações no campo, a Constituição Federal de 1988, em seu artigo 200, estabeleceu que "ao Sistema Único de Saúde (SUS) compete executar as ações de Saúde do Trabalhador [...], colaborar na proteção do meio ambiente, nele compreendido o do trabalho" (BRASIL, 1988). A Política Nacional de Saúde do Trabalhador e da Trabalhadora, instituída pela Portaria 1.823 em 2012, afirma, em seu parágrafo único, alinhar-se com o conjunto de políticas de saúde no âmbito do SUS, considerando a transversalidade das ações de saúde do trabalhador e o trabalho como um dos determinantes do processo saúde-doença (BRASIL, 2012).

A criação da RENAST (Rede Nacional de Atenção Integral à Saúde do Trabalhador), enquanto estratégia do Ministério da Saúde para institucionalização e fortalecimento do campo, teve como objetivo "integrar a rede de serviços do SUS, voltados para a assistência e a vigilância, para o desenvolvimento das ações de Saúde do Trabalhador" (BRASIL, 2005). De acordo com o CREPOP (Centro de Referência Técnica em Psicologia e Políticas Públicas), tal estratégia deu-se, principalmente, por meio de incentivo financeiro aos municípios e estados para a criação de Centros de Referência em Saúde do Trabalhador (CEREST),

Fractal, Rev. Psicol., v. 32 - n. 1, p. 72-81, 2020 que devem desempenhar a função de suporte técnico, de coordenação de projetos e de educação em saúde para a rede do SUS da sua área de abrangência (CREPOP, 2008).

Os princípios e diretrizes que norteiam a RENAST são coincidentes com os da Política Nacional de Saúde do Trabalhador e podem ser resumidos em: I) atenção integral à Saúde dos Trabalhadores; II) articulação intra e intersetoriais; III) informações em Saúde do Trabalhador; IV) apoio ao desenvolvimento de estudos e pesquisas; V) capacitação permanente em Saúde do Trabalhador; e VI) participação da comunidade na gestão das ações em Saúde do Trabalhador (BRASIL, 2004).

Por conseguinte, é importante destacar a participação dos trabalhadores, considerada essencial para a identificação dos fatores de risco presentes no trabalho e das repercussões destes sobre o processo saúde-doença, bem como para a transformação das condições geradoras de acidentes e doença, como afirmam Dias e Hoefel (2005) ao problematizarem a estratégia da RENAST para a atenção à saúde do trabalhador no SUS. Além disso, as diretrizes e princípios já ressaltados devem nortear os procedimentos e atuação profissional no campo, direcionando práticas com vistas a promover e assegurar o bem-estar dos trabalhadores.

\section{Formação em Psicologia: adequada para a atuação em Saúde do Trabalhador?}

A atuação do psicólogo no Brasil tem sido importante objeto de reflexão, em especial no tocante aos questionamentos de sua prática, muitas vezes fruto de uma formação deficitária e reducionista. Nesse sentido, segundo observa Bernardes (2012), as instituições formadoras são reprodutoras de modelos básicos de atuação centrados nas atividades clínicas de consultório particular, dentro de uma perspectiva de formação de profissionais liberais. Geralmente, as dificuldades para uma formação generalista persistem, restando ao graduando optar por uma ou duas especialidades para seu aperfeiçoamento e desenvolvimento do estágio curricular obrigatório (LISBOA; BARBOSA, 2009).

Por conseguinte, constata-se que a formação predominantemente especialista tende a levar o profissional a experimentar limitações para relacionar os diversos saberes da Psicologia, bem como para atuar em contextos que fogem à regra dos procedimentos comumente aplicados nos domínios da área clínica, como pode ser o caso dos psicólogos que têm sua atuação voltada para a saúde do trabalhador. Pode-se citar, como exemplos, a incoerência nas técnicas desempenhadas, nos métodos de avaliação e diagnóstico, nas ações de prevenção de acidentes de trabalho e de promoção de saúde, caracterizando abordagens superficiais que desconhecem as reais dificuldades dos contextos e situações de trabalho (VIEIRA; BARROS; LIMA, 2007).

A respeito do exercício profissional do psicólogo do trabalho e das organizações, o estudo de revisão teórica de Coelho-Lima, Costa e Yamamoto (2011) evidencia que a atuação permanece restrita a um fazer prático e tecnicista, e não a pressupostos ético-políticos, pre- 
valecendo o persistente compromisso com a regulação dos trabalhadores para a promoção da produtividade, a necessária atualização teórica e prática na formação e a prioridade dos currículos para disciplinas e conteúdos eminentemente clínicos, por exemplo. Tal conjuntura revela a necessidade de inovações tanto na formação como na atividade profissional, tendo em vista a estática permanência do psicólogo nos níveis técnicos de ação, como também sua dificuldade para intervir efetivamente em situações que abarquem a saúde do trabalhador.

De todo modo, é preciso reconhecer que o movimento de ruptura com a função reprodutora de objetivos técnicos, que por muito tempo tem delineado e delimitado a prática do psicólogo nos contextos de trabalho, já está em curso. Como sugere Bastos e Galvão-Martins (1990), por ser igualmente profissional de saúde e especialista em relações sociais, o psicólogo necessita lidar com o comportamento humano em suas instâncias individuais e coletivas e, por isso, deve estar profissionalmente preparado para manejar métodos e técnicas de investigação-intervenção dos problemas psicossociais inevitáveis nos diversos contextos de trabalho, principalmente quando o assunto traz à tona questões relativas à saúde nesses ambientes.

\section{Psicossociologia: uma abordagem possível}

A Psicossociologia constitui o conjunto de teorias que amparam as Clínicas do Trabalho; nesta abordagem a ênfase recai sobre os aspectos recíprocos entre o indivíduo e o coletivo, o psíquico e o social. "Considera ainda que os grupos, as organizações e as instituições são mediadores da vida pessoal dos indivíduos e são criados, regidos e transformados por eles" (BENDASSOLLI; SOBOLL, 2011, p. 11). Tal abordagem lança mão de relevantes dispositivos participativos de análise da mudança social, colocando a atividade no centro da intervenção e contribuindo para a compreensão dos processos grupais, das organizações e das instituições.

Bendassolli e Soboll (2011) destacam sua contribuição no tocante à definição de "organização", a qual inclui elementos técnicos e normativos, característicos de uma dimensão simbólica e outra imaginária, bem como uma dimensão relativa à "instituição", definida como um conjunto de signos e de símbolos, de representações e de regras, produto das práticas das relações humanas. Nestas contribuições, é possível identificar claramente aspectos que subsidiam a compreensão da natureza dos vínculos que os indivíduos estabelecem com as instituições e as organizações, com reflexos nas questões de trabalho, atribuindo a tais organismos sociais (grupos, organizações e instituições) o papel de mediador, de transformador da vida pessoal dos sujeitos.

Destarte, tem-se que o objeto de estudo e de intervenção da Psicossociologia é o sujeito no quadro da vida cotidiana. Enquanto intervenção, a abordagem se preocupa em desenvolver o papel do pesquisador-interventor, voltando-se principalmente para a transformação dos organismos sociais. Notadamente, o sujeito é encarado como protagonista da construção de sentido e de mudanças, havendo valorização dos saberes individuais e coletivos nas situações do cotidiano. Conforme observa Carreteiro e Barros (2014), todo trabalho só pode ser efetivado se os que dele participam forem vistos como sujeitos ativos, capazes de produzir sentidos e ações para as situações nas quais estão envolvidos.

No tocante a sua aplicabilidade, a Psicossociologia oferece um conjunto de recursos essenciais para os campos da investigação e da ação, constituído pela articulação entre campo social, condutas humanas e vida psíquica (LHUILIER, 2014). Considerando que esta abordagem pressupõe uma demanda advinda de contextos sociais e não individuais, priorizando, deste modo, os coletivos, técnicas como observação, questionários, entrevistas e grupos de discussão sobre situações de trabalho configuram-se como os dispositivos de análise e intervenção geralmente utilizados, fundamentados por contribuições de diversos campos do conhecimento, a exemplo da Psicologia e das Ciências Sociais.

Mediante o exposto, este estudo buscou identificar, através de uma revisão integrativa da literatura, se a atuação do psicólogo no campo Saúde do Trabalhador tem contemplado os pressupostos da abordagem psicossociológica. Nosso objetivo seguiu para além da necessidade de evidenciar tais dimensões referentes à temática, uma vez que é igualmente nossa pretensão contribuir para o conhecimento relativo às práticas em saúde que vêm sendo desenvolvidas pelo psicólogo nas situações e ambientes de trabalho, as quais ainda carecem de maior divulgação científica e problematizações teórico-metodológicas.

\section{Método}

A revisão integrativa é definida por Souza, Silva e Carvalho (2010) como uma abordagem metodológica de grande importância para o campo da saúde, uma vez que sintetiza as pesquisas disponíveis acerca de determinado(s) fenômeno(s), podendo direcionar ou reorientar práticas com base em fundamentos científicos. Assim, partindo da análise de estudos relevantes, é possível construir sínteses com significativo acúmulo de informações, bem como apontar sugestões de novas pesquisas para aprimoramento da temática.

Seguindo os fundamentos da revisão integrativa (MENDES; SILVEIRA; GALVÃO, 2008), após identificação do tema, definição de objetivos, descritores e plano de trabalho, foi realizada a escolha das bases de dados SciELO (Scientific Eletronic Library Online) e LILACS (Literatura Latino Americana e do Caribe de Informação em Ciências da Saúde). Tal critério de escolha considerou o fato de tais bases reunirem fontes de dados científicos consistentes, significativos e de abrangência global.

A coleta dos dados ocorreu no período de dezembro/2015 a março/2016, adotando o levantamento bibliográfico como técnica de coleta de dados que consiste num apanhado geral dos principais trabalhos já realizados, revestidos de importância, capazes de fornecer dados atuais e relevantes relacionados ao tema investigado. Como estratégia de busca, utilizou-se a seguinte combinação de descritores: saúde do trabalhador 
e psicologia; saúde do trabalhador e psicossociologia; atuação do psicólogo e psicossociologia; atuação do psicólogo e saúde do trabalhador.

O passo seguinte foi colocar em prática os critérios para inclusão e exclusão dos estudos encontrados na literatura, considerando que, no levantamento inicial, foi constatado um total de 469 publicações. Dentre elas, uma quantidade expressiva carecia de uma relação satisfatória com os termos pesquisados, dado que os filtros captam o máximo de informações relacionadas aos descritores pesquisados, apresentando estudos variados que por vezes fogem ao objetivo proposto e/ou não contemplam o tema central da pesquisa. Mediante tal situação, os critérios inclusivos adotados para reunir as publicações condizentes com a proposta da presente revisão foram:

- Inclusivos: período de publicação atual, considerando o intervalo de 2010 a 2015; artigos que priorizavam articulações entre as combinações dos descritores; e pertinência do estudo para o objetivo proposto na revisão.

- Exclusivos: artigos repetidos nos modos de busca utilizados; revisões integrativas da literatura, teses e dissertações; e demais publicações que não apresentaram relevância para o objetivo proposto.
A aplicação de tais critérios resultou na pré-seleção de 46 artigos, levando-se em conta a leitura do título e do respectivo resumo, a fim de que a seleção fosse a mais direcionada e consistente possível. As etapas posteriores incidiram em definir informações a serem extraídas para categorização, avaliar criticamente os estudos incluídos na revisão integrativa, interpretar os resultados e, por fim, discutir e apresentá-los sob a forma de síntese do conhecimento (MENDES; SILVEIRA; GALVÃO, 2008).

\section{Resultados}

Durante a extração das informações e construção da planilha de registro, dos 46 artigos pré-selecionados 15 compuseram o conjunto final para análise na íntegra (Tabelas 1 e 2). Destes, inicialmente observou-se a variedade de referenciais teórico-metodológicos, abrangendo desde revisões teóricas, relatos de experiência e estudos de caso até pesquisas de cunho quantitativo e qualitativo. Nesse sentido, é possível conjecturar que o campo da Saúde do Trabalhador vem sendo abordado sob diversas vertentes, em especial no tocante à atuação do psicólogo e à apreensão da saúde e do trabalho enquanto fenômenos multifacetados.

Ademais, cabe sinalizar a nítida barreira em identificar pressupostos da abordagem psicossociológica conforme o objetivo proposto, o que, por um lado, evi-

Tabela 1. Artigos selecionados pela SciELO

\begin{tabular}{|c|c|c|c|c|c|}
\hline $\mathbf{N}^{\circ}$ & Ano & Título & Autores & Periódico & Tipo de estudo \\
\hline 1 & 2010 & $\begin{array}{l}\text { Psicologia e Profissão: neurose } \\
\text { profissional e a atuação do } \\
\text { psicólogo organizacional } \\
\text { frente à questão. }\end{array}$ & $\begin{array}{l}\text { SANTOS, L. C. } \\
\text { et al. }\end{array}$ & $\begin{array}{l}\text { Psicologia, } \\
\text { Ciência e } \\
\text { Profissão }\end{array}$ & Revisão teórica \\
\hline 2 & 2010 & $\begin{array}{l}\text { Fadiga no trabalho: como o } \\
\text { psicólogo pode atuar? }\end{array}$ & $\begin{array}{l}\text { OLIVEIRA, J. R. S. } \\
\text { et al. }\end{array}$ & $\begin{array}{l}\text { Psicologia em } \\
\text { Estudo }\end{array}$ & Revisão teórica \\
\hline 3 & 2011 & $\begin{array}{l}\text { Resiliência no trabalho } \\
\text { contemporâneo: promoção e/ou } \\
\text { desgaste da saúde mental. }\end{array}$ & $\begin{array}{l}\text { RIBEIRO, A. C. A.; } \\
\text { et al. }\end{array}$ & $\begin{array}{l}\text { Psicologia em } \\
\text { Estudo }\end{array}$ & Revisão teórica \\
\hline 4 & 2012 & $\begin{array}{c}\text { Políticas públicas em saúde mental } \\
\text { e trabalho: desafios políticos e } \\
\text { epistemológicos. }\end{array}$ & $\begin{array}{l}\text { NARDI, H. C.; } \\
\text { RAMMINGER, T. }\end{array}$ & $\begin{array}{l}\text { Psicologia, } \\
\text { Ciência e } \\
\text { Profissão }\end{array}$ & Revisão teórica \\
\hline 5 & 2013 & $\begin{array}{l}\text { Ampliando o diálogo entre } \\
\text { trabalhadores e profissionais de } \\
\text { pesquisa: alguns métodos de } \\
\text { pesquisa-intervenção para o campo } \\
\text { da Saúde do Trabalhador. }\end{array}$ & $\begin{array}{l}\text { RAMMINGER, T.; } \\
\text { ATHAYDE, M. R. C.; } \\
\text { BRITO, J. }\end{array}$ & $\begin{array}{c}\text { Ciência \& } \\
\text { Saúde Coletiva }\end{array}$ & Revisão teórica \\
\hline 6 & 2013 & $\begin{array}{l}\text { Grupo dos Novos: relato de uma } \\
\text { experiência de estágio com grupos } \\
\text { de acolhimento de trabalhadores em } \\
\text { um Centro de Referência em Saúde } \\
\text { do Trabalhador (Cerest). }\end{array}$ & $\begin{array}{l}\text { IMBRIZI, J. M.; } \\
\text { KEPPLER, I. L. S.; } \\
\text { VILHANUEVA, M. S. }\end{array}$ & $\begin{array}{l}\text { Revista } \\
\text { Brasileira de } \\
\text { Saúde } \\
\text { Ocupacional }\end{array}$ & $\begin{array}{l}\text { Relato de } \\
\text { experiência }\end{array}$ \\
\hline 7 & 2015 & $\begin{array}{l}\text { A supervisão enquanto dispositivo: } \\
\text { narrativa docente } \\
\text { do estágio profissional em } \\
\text { psicologia do trabalho. }\end{array}$ & DUARTE, D. A. & $\begin{array}{l}\text { Interface -- } \\
\text { Comunicação, } \\
\text { Saúde, } \\
\text { Educação }\end{array}$ & $\begin{array}{l}\text { Relato de } \\
\text { experiência }\end{array}$ \\
\hline
\end{tabular}


denciou a escassez do conhecimento e a necessidade de maior investimento na temática e, por outro, demandou certo empenho e algumas limitações na escolha do material para compor a presente revisão integrativa.

Para uma análise mais detalhada e consistente, os estudos selecionados foram categorizados com base nas temáticas abordadas e agrupados em três categorias, quais sejam: campo da Saúde do Trabalhador, contendo os artigos de numeração 10, 11 e 12; aspectos teórico-metodológicos presentes no campo, composta pelos estudos numerados por 3, 4, 5, 7, 8 e 9; e atuação do psicólogo em saúde do trabalhador, incluindo os demais achados, identificados pelos números 1, 2, 6, 13, 14 e 15. A seguir, serão apresentadas as discussões correspondentes a cada uma das categorias de análise, bem como apontadas algumas contribuições relevantes e/ou limitações dentre os estudos selecionados.
O estudo de Souto, Batista e Batista (2014) faz ponte com a problemática da formação em Psicologia, em especial no tocante às experiências práticas desenvolvidas no âmbito do SUS, onde se localizam algumas ações interventivas em saúde do trabalhador. Tais autores, analisando a proposta da educação interprofissional, situam-na como ideal para uma formação que priorize o trabalho em equipe, a comunicação interprofissional e a abordagem integral ao sujeito, reunindo assim premissas e princípios que devem ser norteadores das práticas em saúde pública.

Tendo como pano de fundo a Psicologia e o trabalho não regulado, Sato (2013) evidencia a necessidade de incluir, devidamente, a atenção à saúde do trabalhador na política de saúde pública, além do aprimoramento dos estudos sobre desemprego, atividades informais e as ditas profissões esquecidas. Por fim, a realidade dos jovens

Tabela 2. Artigos selecionados pela LILACS

\begin{tabular}{|c|c|c|c|c|c|}
\hline $\mathbf{N}^{\circ}$ & Ano & Título & Autores & Periódico & Tipo de estudo \\
\hline 8 & 2011 & $\begin{array}{l}\text { Demanda por grupos, } \\
\text { psicologia e controle. }\end{array}$ & $\begin{array}{l}\text { SANTOS, A. O.; } \\
\text { CASTRO, E. O. }\end{array}$ & $\begin{array}{l}\text { Psicologia \& } \\
\text { Sociedade }\end{array}$ & $\begin{array}{l}\text { Relato de } \\
\text { experiência }\end{array}$ \\
\hline 9 & 2013 & $\begin{array}{c}\text { Olhar de dirigentes sindicais sobre } \\
\text { qualidade de vida no trabalho e } \\
\text { mal-estar no trabalho. }\end{array}$ & $\begin{array}{l}\text { TODESCHINI, R.; } \\
\text { FERREIRA, M. C. }\end{array}$ & $\begin{array}{l}\text { Estudos de } \\
\text { Psicologia }\end{array}$ & $\begin{array}{l}\text { Estudo descritivo- } \\
\text { exploratório }\end{array}$ \\
\hline 10 & 2013 & $\begin{array}{l}\text { Recuperando o tempo perdido: a } \\
\text { psicologia e o trabalho } \\
\text { não regulado. }\end{array}$ & SATO, L. & $\begin{array}{l}\text { Cadernos de } \\
\text { Psic. Social do } \\
\text { Trabalho }\end{array}$ & Revisão teórica \\
\hline 11 & 2014 & $\begin{array}{l}\text { A educação interprofissional na } \\
\text { formação em Psicologia. }\end{array}$ & $\begin{array}{l}\text { SOUTO, T. S.; BATISTA, } \\
\text { S. H.; BATISTA, N. A. }\end{array}$ & $\begin{array}{l}\text { Psicologia, } \\
\text { Ciência e } \\
\text { Profissão }\end{array}$ & $\begin{array}{l}\text { Pesquisa de } \\
\text { campo quanti- } \\
\text { qualitativa }\end{array}$ \\
\hline 12 & 2014 & $\begin{array}{l}\text { Jovens trabalhadoras e o sofrimento } \\
\text { ético-político. }\end{array}$ & DIAS, M. D. A. & $\begin{array}{l}\text { Psicologia \& } \\
\text { Sociedade }\end{array}$ & Estudo de caso \\
\hline 13 & 2014 & $\begin{array}{l}\text { A escuta do sofrimento psíquico } \\
\text { relacionado ao trabalho. }\end{array}$ & $\begin{array}{l}\text { SILVEIRA, L. C.; } \\
\text { FEITOSA, R. M. M.; } \\
\text { PALÁCIO, P. D. B. }\end{array}$ & $\begin{array}{l}\text { Psicologia em } \\
\text { Revista }\end{array}$ & Estudo de caso \\
\hline 14 & 2014 & $\begin{array}{l}\text { Perícia psicológica no âmbito do } \\
\text { trabalho: atuação numa } \\
\text { diretoria de saúde do servidor. }\end{array}$ & $\begin{array}{l}\text { SILVA, M. P.; SILVA, R. } \\
\text { M.; SILVA, J. K. B. }\end{array}$ & $\begin{array}{l}\text { Psicologia } \\
\text { Argumento }\end{array}$ & $\begin{array}{l}\text { Estudo descritivo } \\
\text { exploratório }\end{array}$ \\
\hline 15 & 2015 & $\begin{array}{l}\text { Aspectos da prática clínica em } \\
\text { Psicologia dirigida à } \\
\text { reabilitação de trabalhadores. }\end{array}$ & $\begin{array}{l}\text { BIASI, E. Y.; } \\
\text { RUMIN, C. R. }\end{array}$ & $\begin{array}{l}\text { Psicologia, } \\
\text { Ciência e } \\
\text { Profissão }\end{array}$ & Estudo de caso \\
\hline
\end{tabular}

\section{Discussão}

\section{Categoria 1: Campo da Saúde do Trabalhador}

Nesta categoria constam 3 artigos que, de modo geral, problematizam o campo da Saúde do Trabalhador enquanto campo de pesquisa e de atuação imbricado de múltiplas dimensões e desafios, no sentido de compreendê-lo para transformá-lo. Cabe salientar, mediante a quantidade de artigos presentes na categoria, os entraves para localizar interfaces do campo com a atuação ou mesmo com a própria Psicologia, embora existam algumas contribuições a serem consideradas. que trabalham em sua relação com questões de saúde e formação para o futuro é discutida por Dias (2014), com base numa perspectiva da Psicologia Sócio-Histórica. As análises levaram a autora a concluir que a inclusão destes sujeitos no processo de produção apresenta, por vezes, o sentido de sofrimento ético-político, caracterizando uma inclusão perversa que afeta diretamente a saúde dos jovens trabalhadores. 
Categoria 2: Aspectos teórico-metodológicos presentes no campo

Nessa categoria, os seis artigos analisados apresentam diversidade na definição dos aportes teóricos, bem como no que se refere às metodologias utilizadas. Pode-se afirmar que esta realidade corrobora as características do próprio campo da Saúde do Trabalhador, como refere Duarte (2015) ao mencionar o desdobramento conceitual que remete à definição desse campo que, por ter abrangência intrassetorial e intersetorial, demanda uma abordagem interdisciplinar e multiprofissional capaz de conjugar saberes diversos, tanto em nível científico quanto do próprio trabalhador.

Lacaz (2007) afirma que o campo é constituído sob a influência de três vetores: a produção acadêmica, a programação em saúde na rede pública e o movimento dos trabalhadores, particularmente a partir dos anos de 1980. Esses vetores conferem dinamicidade ao campo de Saúde do Trabalhador. O autor discute que no vetor da produção acadêmica há maior incorporação de saberes da saúde ocupacional, o que metodologicamente se reflete em reducionismo nas políticas, práticas e produções do campo, que sofre também com o retrocesso do movimento de organização dos trabalhadores no Brasil a partir da década de 1980 (LACAZ, 2007).

Ramminger, Athayde e Brito (2013), ao se debruçarem sobre pesquisa-intervenção em Saúde do Trabalhador, discorrem sobre alguns métodos que enfatizam formas coletivas e compartilhadas de análise das relações que se estabelecem no e com o trabalho, em relação sinérgica com a experiência dos protagonistas deste, tomando como referência a 'enquete operária' de Karl Marx, contribuições de algumas Clínicas do Trabalho - considerando-se a presença de afinidades teórico-metodológicas e diferenças - como o Modelo Operário Italiano de luta pela saúde, a Ergonomia da Atividade e a Psicodinâmica do Trabalho. Segue-se a estes a proposta avançada pela Ergologia - o dispositivo dinâmico de três polos - e uma de suas configurações que vem sendo desenvolvida no Brasil, a Comunidade Ampliada de Pesquisa (RAMMINGER; ATHAYDE; BRITO, 2013).

Os trabalhos de Ribeiro et al. (2011) e Todeschini e Ferreira (2013), por sua vez, trazem em seu bojo aspectos teóricos bastante atuais, considerando que tratam da saúde do trabalhador a partir de conceitos como resiliência, qualidade de vida e mal-estar no trabalho. Os estudos citados privilegiam uma reflexão acerca das repercussões da reestruturação produtiva e seus impactos na saúde do trabalhador. Nesta direção, Ribeiro et al. (2011) enfatizam o papel da resiliência para a saúde ou o adoecimento dos trabalhadores.

Já os achados de Todeschini e Ferreira (2013), voltados para qualidade de vida e saúde no trabalho, apontam a força sindical como instrumento de intervenção e de defesa do bem-estar dos trabalhadores no seu ambiente ocupacional e resgatam a importância das mobilizações da classe operária para ações mais efetivas em prol da saúde nesses ambientes. Para esses autores, os resultados encontrados forneceram bases empíricas para a formulação de recomendações em Ergonomia, visando prevenir as fontes de mal-estar no trabalho. Ademais, foram reforçadas as bases teóricas da Abordagem de Ergonomia da Atividade Aplicada à Qualidade de Vida no Trabalho (EAA-QVT) e o desenho de subsídios para a formulação de políticas públicas neste campo (TODESCHINI; FERREIRA, 2013).

Ao narrar a experiência de supervisão do estágio profissional em Psicologia do Trabalho, Duarte (2015) apresenta a supervisão enquanto dispositivo, ao discorrer sobre o quadro teórico-conceitual que norteou a atuação, bem como a metodologia utilizada. A autora relata que, no decorrer da experiência do estágio, diversas abordagens foram utilizadas numa perspectiva interdisciplinar, sendo estabelecido, como eixo transversal, um arcabouço dialógico que não ignora as divergências e especificidades das correntes teóricas, mas que as trabalha a fim de operar na prática. Entre tais correntes teóricas destacam-se: as Clínicas do Trabalho, com ênfase na Psicodinâmica do Trabalho e na Psicossociologia; a Análise Institucional; a Política Nacional de Humanização (PNH) e seus princípios de transversalidade, indissociabilidade entre atenção e gestão, protagonismo, corresponsabilidade e autonomia dos sujeitos e dos coletivos; e os princípios da saúde pública: universalidade, integralidade e equidade (DUARTE, 2015).

Focando técnicas voltadas aos coletivos, o artigo de Santos e Castro (2011) reflete sobre uma capacitação para o trabalho grupal de equipes de Unidades Básicas de Saúde (UBS). A demanda espontânea, a participação do coletivo, a análise institucional e os aspectos micro e macrossociais remetem aos pressupostos da Psicossociologia, embora não se faça referência explícita à abordagem. O relato do processo de capacitação leva os autores a afirmarem que, talvez pela primeira vez, os sujeitos puderam se perceber como trabalhadores do social, em vez de meros instrumentos do Estado.

Por fim, o último artigo que compôs esta categoria versou sobre as políticas públicas em saúde mental e trabalho. Os autores partem de uma descrição analítica das Conferências Nacionais Brasileiras de Saúde do Trabalhador (CNBST), evidenciando os desafios políticos e epistemológicos que atravessam as formas de legitimação dos saberes-verdades nos campos da Saúde do Trabalhador e da Saúde Mental (NARDI; RAMMINGER, 2012). Ao problematizarem sobre o tema proposto, os autores fazem emergir discussões relevantes sobre os aspectos institucionais e políticos, sobre as questões psicossociais e condições de vida e trabalho dos indivíduos. Nesse sentido, percebem-se aspectos que apontam para uma visão psicossociológica das questões relacionadas ao trabalho e à saúde do trabalhador, contudo, como referido acerca do estudo de Santos e Castro (2011), não há uma alusão direta à abordagem, percebendo-se que parte de seus pressupostos estão presentes apenas nos meandros desses estudos. 


\section{Categoria 3: Atuação do psicólogo em saúde do trabalhador}

A última categoria reúne seis artigos que caracterizam posturas profissionais do psicólogo nas situações e ambientes de trabalho, com ênfase nas intervenções em saúde do trabalhador. De modo geral, existe consenso com relação às atividades de promoção de saúde, prevenção de doenças e reabilitação, uma vez que elas se configuram pilares centrais da atuação do psicólogo, seja nas instituições de trabalho ou mesmo quando este recebe encaminhamentos para atendimento em consultório ou unidades especializadas.

Os resquícios da formação predominantemente clínica podem ser observados nas práticas da psicoterapia individual, anamneses e escutas clínicas citadas nos estudos de Biasi e Rumin (2015) e de Silveira, Feitosa e Palácio (2014), como intervenções pautadas na Psicodinâmica do Trabalho e na clínica psicanalítica. Outras atividades, como avaliação psicológica, elaboração de documentos psicológicos, análises documentais, perícia móvel, estabelecimento de dano psicológico e aconselhamento, também foram observadas mediante análise do processo de perícia psicológica no âmbito do trabalho (SILVA; SILVA; SILVA, 2014).

Tomando por base intervenções mais pontuais em decorrência de síndromes como neurose profissional e fadiga no trabalho, Santos et al. (2010) e Oliveira et al. (2010) corroboram a importância do diagnóstico para o estabelecimento do nexo causal bem como para a identificação das situações conflituosas e potencialmente perigosas à saúde física e mental dos trabalhadores. Para tais autores, a atuação deve ultrapassar o tripé tradicional (seleção, recrutamento e treinamento), congregando ações preventivas, remediadoras, análises ergonômicas, participação/planejamento nos programas de promoção de saúde no trabalho e vistorias mais eficazes.

Muito embora se tenha um panorama de atuações predominantemente marcadas por práticas clínicas, psicoterápicas, individualizantes e sustentadas por técnicas de cunho psicométrico e psicanalítico, o último estudo citado nesta categoria aborda outra perspectiva: intervenção em grupos de acolhimento num Centro de Referência em Saúde do Trabalhador (CEREST/SP). Dessa forma, Imbrizi, Keppler e Vilhanueva (2013) apresentam atividades desenvolvidas com foco em promoção de saúde, como análises das condições de trabalho, observação da dinâmica institucional, visitas com fins de divulgação dos serviços do CEREST e rodas de conversa para acolhimento dos trabalhadores. Nesse caso, o diferencial está na intervenção coletiva que busca quebrar o paradigma do modelo clínico e dos serviços centrados no médico, além de mobilizar o trabalhador como sujeito participativo e transformador do seu contexto de trabalho.

Por conseguinte, observa-se que os fundamentos da Psicossociologia não vêm sendo nitidamente contemplados na atuação do psicólogo em saúde do trabalhador, tampouco são citados dentre os estudos que compõem a presente categoria. Conforme exposto, as intervenções têm se apoiado nos preceitos da Psicodinâmica do Trabalho, da Psicanálise e da Ergonomia da Atividade, bem como têm sido basicamente voltadas às ações de prevenção e reabilitação do trabalhador.

Não obstante, cabe sinalizar sutis contribuições da abordagem no tocante ao trabalho realizado no CEREST (IMBRIZI; KEPPLER; VILHANUEVA, 2013), como, por exemplo, na dinâmica da análise institucional e na intervenção nos grupos de discussão sobre saúde e trabalho (rodas de conversa para acolhimento). Ainda assim, foi possível identificar uma lacuna relativa a tais contribuições, tendo em vista as publicações analisadas. Esta lacuna se expande, sobretudo, nas intervenções clínicas predominantemente individualizadas, quando as demandas coletivas e os riscos psicossociais são quase sempre ignorados.

\section{Considerações finais}

Os artigos analisados nessa revisão integrativa permitiram identificar a ausência de referências à Psicossociologia quanto à atuação do psicólogo em saúde do trabalhador. Outro aspecto relevante que pode ser observado diz respeito à formação ainda expressivamente voltada aos moldes clínicos e ao atendimento individualizado. No que se refere à intervenção, a Psicodinâmica do Trabalho e a clínica psicanalítica encontram lugar de destaque. Provavelmente, a formação em Psicologia pode estar delimitando a intervenção aos moldes da clínica psicanalítica, além da valorização de fatores de cunho operacional e técnico, tendo em vista as produções analisadas.

Considera-se pertinente ressaltar que, mesmo não havendo uma alusão direta à abordagem psicossociológica, nos estudos de Santos e Castro (2011) e de Nardi e Ramminger (2012) foi possível encontrar aspectos congruentes com os princípios desta abordagem, evidenciando-se uma visão psicossociológica das questões relacionadas ao trabalho e à saúde do trabalhador. No relato de experiência elaborado por Imbrizi, Keppler e Vilhanueva (2013), foram identificados subsídios mais consistentes da Psicossociologia, uma vez que as intervenções conduzidas coletivamente em prol da saúde buscaram mobilizar o trabalhador como sujeito ativo e transformador do seu contexto de trabalho.

Reconhecendo que, neste estudo de revisão, foi predominante a escassez de publicações científicas que contemplassem devidamente o uso da abordagem psicossociológica como amparo teórico-metodológico para a atuação do psicólogo nos contextos de trabalho, torna-se pertinente sugerir que tal abordagem, dada sua relevância para a compreensão dos processos grupais, das organizações e das instituições, seja preconizada em pesquisas futuras, mesmo que em condição dialógica com outras perspectivas. É dessa forma que Duarte (2015) menciona tê-la utilizado na sua experiência como supervisora de estágio profissional em Psicologia do Trabalho.

Não obstante, considera-se a ressalva de que a produção do conhecimento em Psicologia, saúde e trabalho não se limita à sua aparição em periódicos de destaque, podendo ocorrer também em distintos espaços sociais. Tomando por pressupostos os limites impostos à abrangência do 
presente trabalho, espera-se minimamente que, no tocante às possibilidades de generalização, os resultados possam extrair importantes análises da produção científica brasileira e, consequentemente, contribuir para o debate sobre a temática, visando à construção, aperfeiçoamento e transformação das práticas em saúde do trabalhador.

A título de recomendação, ressalta-se a importância de um repensar das práticas do psicólogo nos âmbitos institucional e social no sentido de fomentá-las a partir do uso dos pressupostos da Psicossociologia, uma vez que eles ressaltam o protagonismo dos trabalhadores na construção de sentidos relacionados ao trabalho e à percepção das vivências de saúde. Como protagonista, o sujeito é levado a ser um agente ativo na construção dos coletivos, seu fortalecimento e transformação social.

Certamente, não estamos propondo a Psicossociologia como 'ferramenta de salvação', mas alertamos para o fato de se repensar sua aplicabilidade e necessidade de expansão, levando-se em conta que, no âmbito do trabalho, ela viabiliza a compreensão do sujeito na pluralidade dos contextos sociais nos quais está inserido, apontando para a possibilidade de concebê-lo como agente interventor e ativamente capaz de modificar a realidade, tendo em vista sua proposta de articulação entre campo social, condutas humanas e vida psíquica.

\section{Informações sobre as autoras:}

Helyssa Luana Lopes

iD https://orcid.org/0000-0002-4551-211X

(9) http://lattes.cnpq.br/3749714415831762

Possui graduação em Psicologia e mestrado em Psicologia da Saúde pela Universidade Estadual da Paraíba (2012 e 2017, respectivamente), ambos com ênfase em organizações e trabalho. Atuou como professora substituta do Departamento de Psicologia na Universidade Estadual da Paraíba. Tem experiência como supervisora de estágio na área de gestão com pessoas, processos subjetivos e intersubjetivos no mundo do trabalho. Coordenou projeto de pesquisa e extensão voltado ao público adolescente, com foco no desenvolvimento de habilidades sociais e estratégias psicoeducativas. Principais temas e áreas de atuação: psicologia organizacional, saúde mental e trabalho, avaliação psicológica, orientação vocacional e profissional, desenvolvimento humano e psicologia da saúde.

Paula Ramos Oliveira Andrade

(iD) https://orcid.org/0000-0002-3662-8604

(3) http://lattes.cnpq.br/0181837984284492

Psicóloga. Especialista em Terapia Cognitivo Comportametnal UNICORP (em andamento). Mestra em Psicologia da Saúde - PPGPS/ UEPB. Especialista em Gestão de Recursos Humanos - UEPB.

Valéria Morais da Silveira Sousa

(iD) https://orcid.org/0000-0002-9609-7083

(9) http://lattes.cnpq.br/7906164516645705

Mestrado em Psicologia da Saúde pela Universidade Estadual da Paraíba (2017), graduação em Psicologia pela Universidade Estadual da Paraíba - UEPB (2002) - Hab. em Formação de Psicólogo e Licenciatura Plena em Psicologia. Especialista em Recursos Humanos pela Universidade Estadual da Paraíba (2005). Atua com ênfase em Psicologia do Trabalho e Organizacional, principalmente nos seguintes temas: saúde do trabalhador, gestão de pessoas.

\section{Maria Teresa Pires Costa \\ (D) https://orcid.org/0000-0001-9335-3937 \\ (9) http://lattes.cnpq.br/2406703224108111}

Possui graduação em Psicologia pela Universidade Federal do Rio Grande do Norte (1994), Mestrado em Administração pela Universidade Federal da Paraíba (2001), Doutorado em Psicologia, estudando Condições de Trabalho e Saúde do Trabalhador, pela Universidade Federal do Rio Grande do Norte (2012) e PósDoutorado em Psicologia da Saúde pela Universidade Estadual da Paraíba. Atualmente é professora efetiva do Departamento de Administração Pública e Gestão Social da Universidade Federal do Rio Grande do Norte, docente e coordenadora do Mestrado em Gestão Pública do Programa de Pós-Graduação em Gestão Pública do CCSA e do curso de graduação em Administração. Tem experiência na área de Gestão Pública, Gestão de Pessoas, Gestão em Saúde e em Saúde Coletiva com ênfase na Política de Saúde do Trabalhador, tendo participado no período de 2012 a 2014 do Grupo Articulador do Projeto Vidas Paralelas - PVP-RN, iniciativa conjunta dos Ministérios da Saúde e Cultura, coordenado nacionalmente pela UNB. Atuou ainda como como docente na Residência Integrada Multiprofissional em Saúde Materno-Infantil do Hospital Universitário Ana Bezerra no período de 2011 a 2015.

\section{Contribuições das autoras:}

Todos as autoras colaboraram ao longo do processo, desde a elaboração até a revisão final do manuscrito. As autoras aprovaram o manuscrito final para publicação.

\section{Como citar este artigo:}

\section{ABNT}

LOPES, Helyssa Luana et al. Atuação do psicólogo em saúde do trabalhador na perspectiva psicossociológica. Fractal: Revista de Psicologia, Niterói, v. 32, n. 1, p. 72-81, jan./abr. 2020. https://doi. org/10.22409/1984-0292/v32i1/5694

\section{APA}

Lopes, H. L., Andrade, P. R. O., Sousa, V. M. S., \& Costa, M. T. P. (2020, Janeiro/Abril). Atuação do psicólogo em saúde do trabalhador na perspectiva psicossociológica. Fractal: Revista de Psicologia, 32(1), 72-81. doi: https://doi.org/10.22409/1984-0292/ v32i1/5694

\section{Referências}

ALVES, Giovanni; VIZZACCARO-AMARAL, André Luís; MOTA, Daniel Pestana. Trabalho e saúde: a precarização do trabalho e a saúde do trabalhador no século XXI. São Paulo: LTr, 2011.

ANTUNES, Ricardo; ALVES, Giovanni. As mutações no mundo do trabalho na era da mundialização do capital. Educação \& Sociedade, Campinas, v. 25, n. 87, p. 335-351, 2004. Disponível em: http://www.scielo.br/pdf/es/v25n87/21460.pdf. Acesso em: 15 dez. 2015.

BASTOS, Antônio Virgílio Bittencourt; GALVÃO-MARTINS, Ana Helena Caldeira. O que pode fazer o psicólogo organizacional. Psicologia: Ciência e Profissão, Brasília, v. 10, n. 1, p. 10-18, 1990. Disponível em: http://www.scielo.br/pdf/ pcp/v10n1/05.pdf. Acesso em: 15 dez. 2015.

BENDASSOLLI, Pedro Fernando; SOBOLL, Lis Andréa Pereira. Clínicas do Trabalho: novas perspectivas para compreensão do trabalho na atualidade. São Paulo: Atlas, 2011. 
BERNARDES, Jefferson de Souza. A Formação em Psicologia após 50 anos do primeiro Currículo Nacional da Psicologia: alguns desafios atuais. Psicologia: Ciência e Profissão, Brasília, v. 32, n. spe., p. 216-231, 2012. Disponível em: http:/ www.scielo.br/pdf/pcp/v32nspe/v32speca16.pdf. Acesso em: 15 dez. 2015.

BIASI, Evelyn Yamashita; RUMIN, Cassiano Ricardo. Aspectos da prática clínica em Psicologia dirigida à reabilitação de trabalhadores. Psicologia: Ciência e Profissão, Brasília, v. 35, n. 4, p. 1350-1365, 2015. http://dx.doi.org/10.1590/19823703001922013

BRASIL. Constituição (1988). Constituição da República Federativa do Brasil. Brasília, DF: Senado Federal, 1988

BRASIL. Ministério da Saúde. Política Nacional de Saúde do Trabalhador para o SUS. Brasília: MS, 2004. Disponível em: http://bvsms.saude.gov.br/bvs/saudelegis/gm/2012/ prt1823_23_08_2012.html. Acesso em: 22 jan. 2016.

BRASIL. Ministério da Saúde. Portaria $n^{\circ} 1.679$, de 19 de setembro de 2002. Dispõe sobre a Rede Nacional de Atenção Integral à Saúde do Trabalhador (Renast). Caderno de Legislação em Saúde do Trabalhador. 2. ed. Brasília: MS, 2005.

BRASIL. Ministério da Saúde. Portaria $n^{\circ} 1.823$, de 23 de agosto de 2012. Institui a Política Nacional de Saúde do Trabalhador e da Trabalhadora. Diário Oficial [da] República Federativa do Brasil, no 165, Seção I, p. 46-51, 24 de agosto de 2012. Disponível em: http://bvsms.saude.gov.br/bvs/ saudelegis/gm/2012/prt1823 2308 2012.html. Acesso em: 12 de jan. 2016.

CARRETEIRO, Teresa Cristina Othênio; BARROS, Vanessa Andrade. Intervenção psicossociológica. In: BENDASSOLLI, Pedro Fernando; SOBOLL, Lis Andréa Pereira. (Org.). Métodos de pesquisa e intervenção em psicologia do trabalho. São Paulo: Atlas, 2014. p. 101-128.

COELHO-LIMA, Fellipe; COSTA, Ana Ludmila Freire; YAMAMOTO, Oswaldo Hajime. O exercício profissional do psicólogo do trabalho e das organizações: uma revisão da produção científica. Revista Psicologia: Organizações e Trabalho, Florianópolis, v. 11, n. 2, p. 21-35, 2011. Disponível em: http://pepsic.bvsalud.org/pdf/rpot/v11n2/v11n2a03.pdf. Acesso em: 18 jan. 2016.

CREPOP. Centro de Referência Técnica em Psicologia e Políticas Públicas. Saúde do Trabalhador no âmbito da Saúde Pública: referências para atuação do(a) psicólogo(a). Brasília: CFP, 2008.

DIAS, Elizabeth Costa; HOEFELI, Maria da Graça. O desafio de implementar as ações de saúde do trabalhador no SUS: a estratégia da RENAST. Ciência \& Saúde Coletiva, Rio de Janeiro, v. 10, n. 4, p. 817-827, 2005. Disponível em: https:// www.scielosp.org/pdf/csc/2005.v10n4/817-827/pt. Acesso em: 22 de jan. 2020.

DIAS, Maria Dionísia Amaral. Jovens trabalhadoras e o sofrimento ético-político. Psicologia \& Sociedade, Florianópolis, v. 26, n. 2, p. 93-102, 2014. http://dx.doi. org/10.1590/S0102-71822014000600010

DUARTE, Daniele Almeida. A supervisão enquanto dispositivo: narrativa docente do estágio profissional em psicologia do trabalho. Interface-Comunicação, Saúde, Educação, Botucatu, v. 19 , n. 52, p. 133-144, 2015. http://dx.doi.org/10.1590/180757622014.0170
GOMEZ, Carlos Minayo. Campo da saúde do trabalhador: trajetória, configuração e transformações. In: GOMEZ, Carlos Minayo; MACHADO, Jorge Mesquita Huet; PENA, Paulo Gilvane Lopes. (Org.). Saúde do trabalhador na sociedade brasileira contemporânea. Rio de Janeiro: Fiocruz, 2011. p. 23-34.

GOMEZ, Carlos Minayo; LACAZ, Francisco Antônio de Castro GOMEZ. Saúde do trabalhador: novas-velhas questões. Ciência \& Saúde Coletiva, Rio de Janeiro, v. 10, n. 4, p. 797-807, 2005. http://dx.doi.org/10.1590/S1413-81232005000400002

IMBRIZI, Jaquelina Maria; KEPPLER, Isabel Lopes do Santos; VILHANUEVA, Marcelo Soares. Grupo dos Novos: relato de uma experiência de estágio com grupos de acolhimento de trabalhadores em um Centro de Referência em Saúde do Trabalhador (Cerest). Revista Brasileira de Saúde Ocupacional, São Paulo, v. 38, n. 128, p. 302-314, 2013. http:// dx.doi.org/10.1590/S0303-76572013000200017

LACAZ, Francisco Antônio de Castro. O Campo Saúde do Trabalhador: resgatando conhecimentos e práticas sobre as relações trabalho-saúde. Caderno Saúde Pública, Rio de Janeiro, v. 23, n. 4, p. 757-766, 2007. http://dx.doi.org/10.1590/ S0102-311X2007000400003

LHUILIER, Dominique. Introdução à psicossociologia do trabalho. Cadernos de Psicologia Social do Trabalho, São Paulo, v. 17, num. esp., p. 5-19, 2014. Disponível em: http:// pepsic.bvsalud.org/pdf/cpst/v17nspe/a03v17nspe.pdf. Acesso em: 22 de jan. 2020.

LISBOA, Felipe Stephan; BARBOSA, Altemir José Gonçalves. Formação em Psicologia no Brasil: um perfil dos cursos de graduação. Psicologia: Ciência e Profissão, Brasília, v. 29, n. 4, p. 718-737, 2009. http://dx.doi.org/10.1590/S141498932009000400006

MENDES, Karina Dal Sasso; SILVEIRA, Renata Cristina de Campos Pereira; GALVÃo, Cristina Maria. Revisão integrativa: método de pesquisa para a incorporação de evidências na saúde e na enfermagem. Texto \& Contexto Enfermagem, Florianópolis, v. 17, n. 4, p. 758-764, 2008. http:// dx.doi.org/10.1590/S0104-07072008000400018

NARDI, Henrique Caetano; RAMMINGER, Tatiana. Políticas públicas em saúde mental e trabalho: desafios políticos e epistemológicos. Psicologia: Ciência e Profissão, Brasília, v. 32, n. 2, p. 374-387, 2012. http://dx.doi.org/10.1590/S141498932012000200008

NELI, Marcos Acácio. Reestruturação produtiva e saúde do trabalhador: um estudo com trabalhadores de uma indústria avícola. 2006. Dissertação (Mestrado em Saúde na Comunidade) - Faculdade de Medicina de Ribeirão Preto, Universidade de São Paulo, Brasil, 2006.

OLIVEIRA, Juliana Roman dos Santos; VIGANÓ, Magna Gabriella; LUNARDELLI, Maria Cristina Frollini; CANÊO, Luiz Carlos; GOULART JÚNIOR, Edward. Fadiga no trabalho: como o psicólogo pode atuar? Psicologia em Estudo, Maringá, v. 15 , n. 3, p. $633-638,2010$. http://dx.doi.org/10.1590/S141373722010000300021

RAMMINGER, Tatiana; ATHAYDE, Milton Raimundo Cidreira de; BRITO, Jussara. Ampliando o diálogo entre trabalhadores e profissionais de pesquisa: alguns métodos de pesquisa-intervenção para o campo da Saúde do Trabalhador. Ciência \& Saúde Coletiva, Rio de Janeiro, v. 18, n. 11, p. 3191-3202, 2013. http://dx.doi.org/10.1590/S141381232013001100010 
RIBEIRO, Ana Cláudia de Araújo; MATTOS, Beatriz Marques de; ANTONELLI, Carolina de Santi; CANÊO, Luiz Carlos; GOULART JÚNIOR, Edward. Resiliência no trabalho contemporâneo: promoção e/ou desgaste da saúde mental. Psicologia em Estudo, Maringá, v. 16, n. 4, p. 623-633, 2011. http://dx.doi.org/10.1590/S1413-73722011000400013

SANTOS, Abrahão de Oliveira; CASTRO, Edson Olivari de. Demanda por grupos, psicologia e controle. Psicologia \& Sociedade, Florianópolis, v. 23, n. 2, p. 325-331, 2011. http:// dx.doi.org/10.1590/S0102-71822011000200013

SANTOS, Ludmilla Cristine; GOULART JÚNIOR, Edward; CANÊO, Luiz Carlos; LUNARDELLI, Maria Cristina Frollini; CARVALHO, Pérola Lozano Teixeira de. Psicologia e Profissão: neurose profissional e a atuação do psicólogo organizacional frente à questão. Psicologia: Ciência e Profissão, Brasília, v. 30, n. 2, p. 248-261, 2010. http://dx.doi.org/10.1590/S141498932010000200003

SATO, Leny. Recuperando o tempo perdido: a psicologia e o trabalho não regulado. Cadernos de Psicologia Social do Trabalho, São Paulo, v. 16, n. spe. 1, p. 99-110, 2013. https:// doi.org/10.11606/issn.1981-0490.v16ispe1p99-110

SELIGMANN-SILVA, Edith. Trabalho e desgaste mental: o direito de ser dono de si mesmo. São Paulo: Cortez, 2011.

SILVA, Mariana Pinheiro da; SILVA, Rosana Marques da; SILVA, Janaina Karpinski Baptista da. Perícia psicológica no âmbito do trabalho: atuação numa diretoria de saúde do servidor. Psicologia Argumento, Curitiba, v. 32, n. 79, p. $15-$ 25, 2014. Disponível em: https://pesquisa.bvsalud.org/portal/ resource/pt/li1-754708. Acesso em: 12 abr. 2016.

SILVEIRA, Lia Carneiro; FEITOSA, Rúbia Mara Maia; PALÁCIO, Paula Danyelle Barros. A escuta do sofrimento psíquico relacionado ao trabalho: contribuições da psicanálise para o cuidado em saúde. Psicologia em Revista, Belo Horizonte, v. 20, n. 1, p. 19-33, 2014. Disponível em: http:// pepsic.bvsalud.org/pdf/per/v20n1/v20n1a03.pdf. Acesso em: 2 fev. 2016.

SOUTO, Thamires da Silva; BATISTA, Sylvia Helena; BATISTA, Nildo Alves. A educação interprofissional na formação em Psicologia. Psicologia: Ciência e Profissão, Brasília, v. 34, n. 1, p. 32-45, 2014. http://dx.doi.org/10.1590/ S1414-98932014000100004

SOUZA, Marcela Tavares de; SILVA, Michelly Dias da; CARVALHO, Rachel de. Revisão integrativa: o que é e como fazer. Einstein, São Paulo, v. 8, n. 1, p. 102-106, 2010. Disponível em: http://www.scielo.br/pdf/eins/v8n1/pt_16794508-eins-8-1-0102.pdf. Acesso em: 15 fev. 2016.

TODESCHINI, Remígio; FERREIRA, Mário César. Olhar de dirigentes sindicais sobre qualidade de vida no trabalho e malestar no trabalho. Estudos de Psicologia, Brasília, v. 18, n. 2, p. 241-247, 2013. Disponível em: http://www.scielo.br/pdf/epsic/ v18n2/v18n2a09.pdf. Acesso em: 15 fev. 2016.

VIEIRA, Carlos Eduardo Carrusca; BARROS, Vanessa Andrade; LIMA, Francisco de Paula Antunes. Uma abordagem da psicologia do trabalho, na presença do trabalho. Psicologia em Revista, Belo Horizonte, v. 13, n. 1, 155-168, 2007. Disponível em: http://pepsic.bvsalud.org/pdf/per/v13n1/ v13n1a10.pdf. Acesso em: 15 fev. 2016. 